How to cite this article:

Yusof, N., Tengku Ariffin, T. F., Awang-Hashim, R., Nordin, H., \& Kaur, A. (2020). Challenges of service learning practices: Student and faculty perspectives from Malaysia. Malaysian Journal of Learning and Instruction, 17(2), 279-309. https:// doi.org/10.32890/mjli2020.17.2.10

\title{
CHALLENGES OF SERVICE LEARNING PRACTICES: STUDENT AND FACULTY PERSPECTIVES FROM MALAYSIA
}

\author{
${ }^{1}$ Norhafezah Yusof, ${ }^{2}$ Tengku Faekah Tengku Ariffin, \\ ${ }^{2}$ Rosna Awang Hashim, \\ ${ }^{2}$ Hasniza Nordin \& ${ }^{2}$ Amrita Kaur \\ ${ }^{1}$ School of Multimedia Technology and Communication, \\ ${ }^{2}$ School of Education and Modern Languages \\ Universiti Utara Malaysia, Malaysia
}

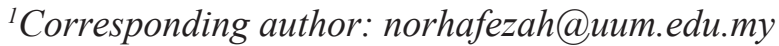

Received: 19/4/2020 Revised: 11/7/2020 Accepted: 19/7/2020 Published: 31/7/2020

\begin{abstract}
Purpose - The main purpose of service learning is to produce holistically developed students. Since 2015, the Ministry of Higher Education has mandated the infusion of service learning into various study programs, however till today, service learning across the country is still in its infancy. Critical insights on its contextual compatibility is not fully understood within the Malaysian context. Therefore, this paper aims to highlight the perspectives of lecturers and students on the challenges they have encountered when participating in service learning.
\end{abstract}

Methodology - This study employed a qualitative approach, and incorporated the principles of Scholarship of Teaching and Learning (SoTL) that guided data collection from the participants. The students and lecturers who participated in the study were selected using purposive sampling techniques. The data from the students were collected through focus group interviews, while in-depth face to face interviews were conducted to collect data from the lecturers. 
The two sources of data were then analysed using a thematic analysis method.

Findings - Based on the analysis of the perspectives from students, the challenges encountered were as follows: 1) there is a gap in the understanding between theory and practice, and 2) the lack of cognitive autonomy. On the other hand, the main challenge identified based on the perspectives of the lecturers is the lack of structural support. Moreover, the common challenges experienced by both participants are the relationship and rapport with the community.

Significance -These findings provide insight into the challenges faced by lecturers and students in a public university where service learning is practised. These insights would provide necessary information to academic developers that provide training workshops on service learning, and to lecturers that are involved in the design and implementation of service-learning projects.

Keywords: Service learning, teaching and learning, higher education, SoTL.

\section{INTRODUCTION}

Service learning is experiential learning that integrates practical experiences into the academic curriculum. Its theoretical and practical foundations stem from experiential education and constructivism, whereby these two fields of study have helped frame service learning as an opportunity for students to apply their knowledge within the community (Furco, 2001), and includes community engagement and the educational benefits of experiential learning (Parker et al., 2009).

Service learning encourages students to be creative when applying their knowledge and skills learned in the classroom to resolve issues and challenges encountered in the community. The students are guided by their lecturers when undergoing service learning in a selected community. Students will begin by gaining an understanding of the needs of the community, and would then identify the problems related to those needs. Subsequently, the students would offer practical solutions and will work together with the community 
to solve the problems. They learn to identify the issues within the community and engage to rectify the problems faced by the community, often with the cooperation of co-partners such as the community itself, authority bodies or industrial participants (Felten et al., 2016). It is a rich and comprehensive learning process where knowledge transfer happens during the implementation process. The main purpose of service learning is to produce holistically developed students who are able to think, act and reflect based on empirical evidence and human values (Furco, 1996). It is an immersive learning experience that promotes high impact practices in a curriculum that caters for the development of critical thinking skills, people skills, innovativeness, entrepreneurial mindset, resilience with cognitive flexibility, emotional and contextual intelligence, and passion for lifelong learning (Kilgo, Ezell Sheets \& Pascarella, 2015; AwangHashim, Kaur \& Valdez, 2019).

In recent years, there has been a surge in the implementation of high impact educational practices, including service learning approaches around the world (Conway, Amel, \& Gerwien, 2009; Celio, Durlak, \& Dymnicki, 2011; Xu, Li \& McDougle, 2018; Salam et al., 2019; Bringle \& Clayton, 2020). However, to yield similar beneficial outcomes, the academic systems around the world have consistently reviewed their approaches of such practices to examine contextual compatibility, and identify the challenges that might limit its applicability or recognise similar benefits in different contexts (Butin, 2006; Taylor, 2017).

In Malaysia, the current educational blueprint has included initiatives toward enhancing service learning, as this pedagogical approach is seen as the means to achieve the national educational goals of producing graduates with the necessary skills for employability (Malaysian Education Blueprint, 2015-2025). The implementation of service learning is at the stage where it needs to be incorporated in a more structured and systematic manner into the academic program (Ministry of Education Malaysia, 2015).

This endeavour is now recognised as the 'third mission' for universities across the nation. Therefore, the Ministry of Higher Education has recently devised a set of national guidelines on service-learning implementation in Malaysian universities, which is known as 'SULAM' (Service Learning Malaysia - University for 
Society) (Department of Higher Education, 2019). Moreover, some universities in the country have also created their own specific set of service-learning guidelines which are deemed to be better suited to their specified context. This is in line with the study conducted by Mackenzie, Hinchey and Cornforth (2019), and further asserts that service-learning strategies should be aimed at creating a sustainable environment for cooperation between the university and community. Hence, significant efforts should be geared towards the ideal implementation of service learning within the academic curriculum.

However, as service learning is a fairly new pedagogical approach, its practical implementation has faced significant challenges, particularly within the Malaysian context. These contextual issues may have impeded its impact. The main objective of this paper is to review the common challenges surrounding service learning around the world, and to apply these insights as an analytical framework to highlight the specific issues faced by service-learning practitioners in the country. Moreover, these findings is expected to contribute towards enhancing the effectiveness of this approach in the Malaysian tertiary education system.

\section{The Outcomes of Service Learning}

Various research on service-learning implementations have shown a wide range of outcomes that are associated with student engagement with their communities. From a survey of 1,066 alumni from 30 campuses conducted by Richard, et al., (2018), the findings revealed that dialogue across different cultures was the strongest predictor in sustaining civic engagement outcomes after the students involved had graduated from college. The study suggested that, through service learning, students had the opportunity to engage with individuals who were different from them, which subsequently created the impetus for students to continue to serve the community after their university years. Additionally, students had the opportunity to study the relationship of their own participation in academic, co-curricular programs and post-college civic engagement.

Other valuable outcomes that relate to real work-life experiences might include resolving conflicts through critical thinking and deepthinking abilities (Jelinek, 2016). In a study conducted by Wang, et 
al., (2012) on leadership and service learning of first-year female engineering students, it was suggested that leadership skills could be acquired through service learnings. Therefore, service learning offers opportunities to develop life skills, and enhance academic attainment and civic responsibilities among students (Sax \& Astin, 1997, Hoxmeier \& Lenk, 2020). Students who participate in service learning tend to acquire life skills such as deep reflection and problem-solving (Ahmad, Said \& Mohamad Nor, 2019). They are likely to be more prepared and would review course materials to help them resolve issues within the community. In addition, these students tend to be more open-minded and empathetic on the needs of the community, which led to a better understanding of the world around them. Furthermore, it was suggested that students who participated in service learning became more open to diversity and multiple perspectives (Pike, Kuh, \& McCormick, 2010; Nishimura \& Yokote, 2020) as the experiential learning provided opportunities for students to interact with people from different backgrounds and needs. This enabled students to develop their sense of civic responsibility, and promoted ethical and respectful engagement with the communities that they served.

\section{The Challenges of Service Learning}

Despite its many advantages, service learning has its fair share of challenges when it comes to execution. It was found that the service learning implementation in a university might be hampered if the university's eco-system failed to work synergistically to support the educational institution, instructors and students, and also the community (Salam et al., 2019b; Nishimura \& Yokote, 2020). Karasik (2004) highlighted the five main challenges faced by educational institutions when implementing service learning, which are: pedagogy, community, students, faculty, and the university. Pedagogy was closely related to the role of the faculty to develop and deliver service-learning based curriculum to the students. Students are regarded as an important entity in service learning as they drive service-learning activities. Service learning allows students to engage with the community to solve problems. Thus, faculty and students might sometimes encounter challenges when collaborating with the community as both sides would have a different understanding/ perspective on the issues that require specific solutions. 
Therefore, a university that hosts a service-learning curriculum must be prepared, both structurally and intentionally, to implement their respective projects. Conversely, problems will arise if the university administration that has embraced service-learning programs do not implement well planned procedures and supports, and lack the pedagogical preparedness, particularly with regards to the curriculum design and delivery. Hence, it is important that both the university administration and institutional pedagogical approach must be compatible to create an impactful service learning environment for the students (Chng, Leibowitz \& Mårtensson, 2020).

In the study conducted by Ziegert and McGoldrick (2008), the authors highlighted the perspectives of the instructors and listed out the areas of concern when carrying out service learning. These included the challenges of integrating service learning with the course content, the role of the instructor, preparation time, and assessment. Some instructors believed that the incorporation of service learning into their courses will lead to a loss of focus by the students on the academic content, while other instructors were afraid of losing control over the students' learning while being away for community engagement. A number of instructors had experienced distress over the challenges of matching students' skills with the specific needs of the community, and found it to be time-consuming. Similarly, they also suffered significant levels of stress when supervising the service learning activities of their students in the field.

Bennett(2016) addressed the significance of institutional commitment that included the following factors: structure, process and funding, and resolution of the stakeholders' will power to engage in servicelearning projects. In the absence of these factors, all parties involved in the service-learning project would have wasted their efforts, time and energy. Additionally, clear communication is vital for the successful implementation of service-learning. Morin (2009) asserted that the major pitfall among students was the lack of communication with their peers, instructors or clients. These issues were likely the consequences of the students' inexperience when dealing with other people over technical matters, the time constraints when setting up meetings with friends, lecturers or clients, and the students' lack of expertise or skills to finish the project successfully.

Yusop and Correia (2013) further supported the notion of the mental stress when completing service-learning projects among 
students. Additionally, students participating in service learning would sometimes exhibit emotional outbursts that resulted from the intense cognitive and physical labour that was expected of them. With relation to the community, it was suggested that a short-term service learning program is inadequant to achieve the twofold benefits of meeting students' educational purposes and satisfying the community's needs (Tyron et al., 2008).

Borgerding and Canigla (2017) asserted that despite the benefits of service learning, there was a need to consider the students' readiness and the crucial support that is required from the institutions. The students were considered pre-service teachers, however upon graduation, they had lost the motivation to practice service learning. On the other hand, the lecturers complained of the constant need to supervise the students during service learning projects. It was further suggested that the lack of resources from the educational institution hampered the implementation of service-learning projects.

\section{The Current Context}

The service learning program in higher education was primarily led by academics in the West (see Bringle \& Hatcher, 1996, 2000; Butin, 2003). The implementation of high impact practices in higher education, including service learning in western countries, has shown a positive impact on the students' development. However, universities across the globe have come under scrutiny by various stakeholders regarding their role and ability to produce graduates who are employable, and are equipped to contribute as responsible citizens towards local communities and the nation (Kagan \& Diamond, 2019). Hence, the incorporation of service learning into the curriculum is conceptualised as the third mission of the university (Department of Higher Education Malaysia, 2019). In other words, the Malaysian Higher Education Institutions (HEI) seek answers to questions like; have universities done enough to create impact and develop the local community?, is the existence of the university felt by the community?, and how could universities play better roles in developing the community together with other stakeholders? Within the context of Malaysia, service learning that stems from the university-wide third mission, i.e. the need for HEI to achieve a significant impact on community transformation by developing a sustainable service learning relationship with the selected communities (OECD, 1996). 
Service learning in Malaysia has continued to remain in its infancy, although all higher education institutions have been mandated to incorporate service learning into their study programmes since 2015 (Ministry of Education Malaysia, 2015, see letter from JPT). Within Malaysia, a thorough review of the various literature conducted points to a limited numbers of studies that have measured the impact of service learning practice and the challenges associated with it. An overview of those studies is summarized in Table 1.

\section{Table 1}

Sampling of Service-Learning Studies in Malaysia

\begin{tabular}{ll}
\hline Authors and title of the studies & Findings \\
\hline Khan and Jacob (2015) & Engaging with the selected \\
Service learning for pharmacy & community was an enriching \\
students: Experience of a home- & experience for the students. The \\
grown community engagement involved tasks and assessments \\
elective unit & incorporated service learning \\
& activities that have improved \\
& students communication skills. \\
& In addition, the students benefitted \\
& through the development of \\
& empathy skills and leadership \\
& abilities that are valuable for their \\
& future career and life.
\end{tabular}

Jacob, Palanisamy and Chung (2017)

Perception of a privilege walk activity and its impact on pharmacy students' views on social justice in a service learning elective: A pilot study

Musa et al., (2017)

A methodology for implementation of service learning in higher education institution: A case study from faculty of computer science and information technology, Unimas.

Students understood the differences in privilege among their peers. Several students acknowledged that the session enhanced their reflective skills and made them less judgemental towards the underprivileged.

The study proposed a working methodology on service-learning implementation in Unimas. There were three phases involved, which are: Phase 1 (Planning, Analysis and Design), Phase 2 (Delivery) and Phase 3 (Evaluation, Reflection and Monitoring) 
Huda et al., (2018)

Transmitting leadership based civic responsibility: Insights from service learning

Salam et al., (2019a)

Technology integration in service learning pedagogy: A holistic framework

Salam, et al., (2019b)

Service learning in higher education: A systematic literature review
It is a systematic literature review of civic-based leadership from a service-learning perspective. The findings suggested three cores: 1). strategic planning of community engagement projects; 2). creative thinking and professional skills with experiential leadership; and 3). rational problem-solving using leadership skills and knowledge.

Institution readiness is vital, in the context of providing a reliable technological platform for servicelearning assessment. Problems arose when lecturers were needed to provide assessment for reflection tasks for a big class due to the lack of technology support and knowledge on using the platforms.

The study provides a comprehensive review of service-learning literature in higher education. The findings revealed that servicelearning benefited the relevant stakeholders as most disciplines have incorporated service learning into their pedagogical strategies. Apart from that, the findings of this study suggests that technological integration aspects were lacking during the implementation of service learning in various disciplines.

The overview of the various studies conducted suggests that the effects of the implementation of service learning is currently limited as most investigations were focussed on measuring the effectiveness and learning outcomes of service learning. Given the novelty of this practice in the Malaysian context, it is crucial to understand the mechanics of its implementation with regards to the challenges and opportunities encountered both by lecturers and students. Nevertheless, the literature on service learning, both within 
Malaysia and abroad, suggests that the key aspect of service learning comprises the integration of community service into academic learning, whereby parallel development and partnership between the community and the students occur in a natural ecosystem (Bringle, et al., 2016). Moreover, it highlights the role of pedagogical innovation and effectiveness through the incorporation of the components of service learning to achieve its learning outcomes. Thus, reflective practice is key to ensure successful implementation of service learning. This study focuses on critical reflections from lecturers and students that seek to understand the mechanics of service-learning implementation, in relation to its challenges and opportunities in a Malaysian context.

The role of critical reflections by both learners and instructors/ facilitators is central to identify effective outcomes during the implementation of service learning. This reflective approach would enable a better understanding of the conceptualization and development of effective service learning practices. Therefore, by employing the Scholarship of Teaching and Learning (SoTL) method to investigate service learning practices, the issues and challenges that resulted from its implementation could be investigated. SoTL is defined as a systematic investigation of teaching and learning by employing validated criteria of scholarship to understand the factors that can enhance learning outcomes, or develop accurate understanding of learning which is shared to the academic community (Hutchings \& Shulman,1999; Shulman, 2001). Hubbal and Clarke (2010) offered a heuristic model to investigate potential SoTL research questions. Based on this framework, this study focuses on investigating SoTL process questions that facilitates formative assessment of educational initiatives in a particular context.

By placing the key stakeholders within the framework, this would provide an alternative vantage point from a teaching and learning perspective in SoTL studies as it could help determine better guidelines on the management of service learning in the higher education system. The participants engaged in systematic reflective practice and their experiences on the implementation of service learning were documented. More specifically, the research in question was guided by the following concern: What are the faculty and students' challenges in implementing service learning, in the context of higher education in Malaysia? 


\section{METHODOLOGY}

\section{Research Design}

This study employed a qualitative approach in the collection of data by conducting in-depth face to face interviews and focus group sessions. The interviews and focus group protocols were developed from the literature review and were verified by experts. The methodology for this study incorporated the principles of SoTL that encourages systematic academic inquiry in the teaching and learning practices within classrooms, and to share these findings with other academicians and practitioners for the benefit of all (Felten, 2013). Specifically, this study utilizes Gibbs' Reflective Cycle (1988), based on Kolb's Experiential Learning, to examine the impact of reflection on service-learning practices from the lecturers' (participants) knowledge and their pedagogical practices. This study was designed in the following phases:

\section{Phase-1}

Reflection by researchers on plausible issues that are related to service-learning implementation was carried out (misconceptions on service learning, haphazard practices, and limited references on local best practices were among the related issues examined). In the first meeting, training was conducted to reflect on issues faced by participants in their previous experiences of service-learning implementation. The participants were exposed to standard practices of service learning both locally and internationally. They discussed and provided feedback to the standard and procedures of service learning that was needed to be implemented in the forthcoming semester.

\section{Phase-2}

In this phase, the participants implemented the standard servicelearning procedures and practices. They reflected on their experiences during the second meeting. The focus of this phase was on the enhancement of service-learning practices and conception (reflection-on-action).

\section{Phase-3}

Reflection by researchers on issues related to service-learning practices, and the effectiveness of service-learning implementation 
that was achieved through proper guidance. The five-step guideline for reflections (Gibbs, 1994) were discussed in-depth during the sessions, and served as guidance for reflective writing by the participants.

Samples of reflection questions based on the guidelines by Gibbs (1988) are shown below:

\section{Experience}

Describe your experience by drawing your attention to the facts or order of events. Put yourself back in the situation and try to relive the experience.

Ask yourself, what did you see?

What did you hear?

How did you feel? Etc.

\section{Reaction}

Write your experiences on how you reacted physically, mentally or emotionally. The distinction between your physical, mental and emotional reaction is that of a hand, head and heart response or in other words:

What did you do physically? (physical movements)

What were your logical and reasoned thoughts? (mental)

What was your emotional response? (emotional)

\section{Analysis}

When analysing, consider the component parts that made up the experience.

For example, if you were managing a situation, who was involved?

What issues, problems or topics existed?

Was the time of the day significant?

\section{Interpretation}

Ask yourself, what does this mean to you?

Where did you fit in the big picture?

Are you happy with this?

\section{Action Plan}

What will you do differently in the future?

\section{Participants}

This study was conducted at a university in the North of Malaysia. The researchers involved in the study had conducted a series of 
training on service-learning approaches throughout the year in 2019. A purposive sampling method was utilized to select the respondents for this study. The participants were selected based on two main criteria: 1) they have undergone at least one cycle of service-learning training organised at the university level, and 2) they have applied service learning pedagogical approach in their courses.

Based on these two criteria, eight lecturers were selected. The lecturers were from diverse fields of study, namely; Business Management, Creative Industry Management, Communication, Social Work Management, and Computing Studies. In total, the eight lecturers had a pool of 39 students who took part in their respective service-learning projects. Most of the students were in their final year of studies. The students selected were based on the lecturers' recommendation of their active involvement in their respective service-learning projects. The number of students varied due to program allocation for the student intake in each semester.

\section{Data Collection Procedure}

Institutional permission was first obtained to conduct this study. The selected lecturers and students were informed that their participation was voluntary. All respondents understood that they were free to leave the study and not participate if they ever felt uncomfortable with the questions, or experienced any discomfort during the course of their participation. Moreover, no compensation was provided for the lecturers' participation, while the student participants were given a monetary token of appreciation for their contribution in the focus group. It is suggested that any forms of incentive provided for students' work as compensation for their time and contribution is linked to genuine participation in research studies (Kelly et al., 2017)

Data from the students were collected through focus group interviews. The interviews were conducted in a group. Each focus group was comprised of five to seven participants. Focus group discussions were used to analyse the perspective of the students involved. Based on the guidelines from Krueger and Casey (2015) on focus group, the researchers conducted the session with the aim of obtaining the authentic viewpoints of the participants' experiences in service learning activities or projects. Each focus group session 
lasted between 45 minutes to one and a half hours. Some examples of the questions asked in the focus groups included the following: 'Can you elaborate on your course? Can you tell me what course are you taking and what kind of activities have you participated in the service learning lessons that you took?'

The data from lecturers were collected through in-depth face to face interviews. The in-depth interviews followed open-ended protocols. It was conducted to ensure that the researchers were able to obtain as much information as possible from the respondents (Lindlof \& Taylor, 2002). Each session lasted between 40 minutes to one hour. Some examples of interview questions for the lecturers were as follows: 'Can you elaborate on your course and service-learning activity/project? What issues did you have in integrating the course contents in your service-learning project? All these sessions were recoded, and was later transcribed.

\section{DATA ANALYSIS}

From the guidelines presented by Braun and Clarke (2013), a thematic analytical approach was employed in this study. The two data sources were analysed concurrently while taking into account the research question posed in this study. The thematic analysis was categorised into six main phases. Firstly, the researchers must examine the data thoroughly. At this stage, reviewing data with the theoretical framework is helpful to facilitate the interpretation of the data. Secondly, codes were established based on the data. The researchers began constructing initial codes to provide a better understanding of the data. Thirdly, the themes were identified. After the initial codes were established, these codes are combined and cross referenced to develop meaningful themes. Fourthly, the themes were reviewed based on the initial works of searching for themes from other literature. Fifthly, the themes were finalized with given names. In the final stage, a comprehensive report based on the outcomes of coding and themes were produced.

Essentially, it was a team effort between the research team members with the help of a research assistant who individually coded the interviews with the lecturers (participants) and focus group, and later came together to compare the coding outputs. Subsequently, the team 
reviewed the coding and assigned them to their respective emerging themes, and ensured that the patterns of the data were consistent with the concurred interpretation from the members of the research team. The data was then triangulated using the two sources to ensure that the themes were aligned with the groups' consensus.

\section{FINDINGS}

This study investigated the perspectives of lecturers and students on the challenges they encountered while participating in a servicelearning program. Thematic analysis of the data proposed a total of five themes from all participants. The challenges encountered from the students' perspectives involved the following two themes; 1) Gap in theory and practice, and 2) Lack of cognitive autonomy. The challenge encountered from the lecturers' perspectives was the lack of structural support.Moreover, a theme was identified from the common challenges faced by both lecturers and students, which are relationship and rapport with the community.

\section{Challenges from Students}

\section{Gap in theory and practice}

The main challenge identified from the students' experiences is the lack of any close association between what has been learnt in the classroom, and what needs to be implemented in a practical situation. When the students were asked on the effectiveness of carrying out their service learning projects, most of them responded that they did not know the strategies or have the sufficient skills to apply their theoretical knowledge in a practical setting.

"(My)(Knowledge) in theory is adequate. But how can I apply it? We learn everything in theory. So, when we faced the real situation, we would have to take time to digest (the situation) and adjust ourselves (to practice it) because we're too used to learning only the theoretical bit. Theoretical knowledge is more structured. When we're in the field, things come in different forms; thus it takes time for us to understand what we need to do." [Student 10] 
The students were constantly struggling to apply the theoretical knowledge that they had gained in the classroom to real life situation. As one student remarked, "We are trying to think of ways to use the knowledge gained in the class, to apply in our field allocation". [Student 9]

The students also mentioned the difficulties offinding appropriate field contexts that are related to the contents learnt in the classroom.

"When we were informed about the task, we were told that we needed to be a consultant for a company's strategic planning. However, there was a misunderstanding between us and the company, even though we had explained about our task objective. They asked us to distribute flyers to the potential customers. Later, we tried to explain about our goal again. It is indeed hard to understand and materialised service-learning project."

[Student 35]

Thus, it was not always certain that students will obtain near perfect field conditions to solve problems or contribute with the limited knowledge that they have gained in their classrooms.

\section{Lack of cognitive autonomy}

While various literature have pointed to the benefits of servicelearning in the development of higher order cognitive skills, the students in this study expressed their inability to operate independently when undertaking service-learning projects. They stated that they are highly reliant on their lecturers for guidance, for example, a student said that, "In terms of knowledge of the programme (service learning project), we rely $100 \%$ on our lecturer to explain what volunteerism is because most of us did not have any experience to carry it out."

\section{[Student 02]}

The students displayed a lack of confidence in independent decision making and evaluative judgement ability, and were constantly dependent on guidance. For example, one student said,

“... as I said, when we had to apply the knowledge (in the real setting), we need to have additional knowledge from the Professor 
(who taught us), for example his own experience... so that we can gain some ideas on how to plan (the service learning project) ahead."

[Student 11]

Additionally, the students showed a lack of behavioural and decision making abilities. They emphasised the need of modelling that displayed a clear and concise set of guidelines required to carry out the project independently.

"For those (students) who have zero experience in conducting community work or volunteering, they wouldn't know how to handle service learning projects with any clear guidelines. They must be willing to participate and cooperate. Furthermore, they must make decisions and not rely on others too much."

[Student 03]

Some students spoke about their apprehension of taking independent decisions without consultation with their lecturers. "We consult our lecturers most of the times." [Student 31]. They expressed the need to seek constant guidance from their lecturers, which is contrary to the purpose of the service learning's expected outcomes. "Our lecturer stays with us throughout the whole event" [Student 30]

\section{Challenge from Faculty}

\section{Lack of structural support}

Another significant challenge identified was the lack of structural support, in relation to extra manpower, time, money and planning. The lecturers believed that this support would have made the implementation of service-learning to be more effective. Most lecturers voiced their concern over the implementation realities of service learning. For example, some lecturers expressed their concern on the financial constraints and other structural challenges faced when implementing service learning.

"Many academicians are reluctant to conduct Service Learning activities as it takes a lot of time in planning and delivering the project. Also it involves money. But to me, service learning activities are very important in building and polishing students' soft skills." [Lecturer A] 
Furthermore, the lecturers found it difficult to incorporate service learning into scheduled classrooms as it involved the participation of outside communities. A sample extract from a lecturer illustrates this issue:

"The current syllabus is already packed and not easy to incorporate service learning in each programme. Some topics should be dropped to accommodate service-learning approach. We are struggling to finish the syllabus and students have a tight schedule. We need to manage the suitability of the service learning projects so that it will not interfere with the class time."

[Lecturer G]

Another issue faced by the lecturers was the lack of management/ administrative support. They suggested that time constraint and the number of students per class were among the factors that made it difficult for the implementation of service learning projects.

"A smaller class is preferable. It will make the students to be more critical where they can foresee things. So rather than $40-50$ students, the maximum should be 30 students only. This is because the students have many ideas for us to discuss. Thus, with one-anda-half-hour class, our discussion time is limited. We can only do surface discussion, a bit here and there. However, even with this touch and go concept, we could manage it as we had been consistently doing our discussion."

[Lecturer E]

Apart from that, the lecturers shared their concern on the lack of guidelines. To date, there is no specific set of institutional guidelines on service learning. Therefore, the lecturers were unsure on the amount of time that was needed for the project to be effective and the extent of the project within the community. They expressed the need for more structured guidelines for assessment that would ensure the appropriate learning outcomes are satisfied by the students, and to simultaneously provide the necessary service to the community.

"We also are puzzled with this matter; to what extent is the rigour of the task assigned for service-learning implementation we need to know how to assess the projects. There was no standard rubric for assessment; however, reflections are valuable evidence. Thus, 
it is important to know the alignment of the course syllabus and the SULAM projects. Moreover, balancing between course requirements, community needs, and self-satisfaction is vital. Thus, we need to justify the need to review the curriculum to fit SULAM." [Lecturer $\mathrm{H}$ ]

\section{Common Challenges}

\section{Relationship and rapport with community}

The last theme that was identified from the data involved other important groups of stakeholders that are included in the implementation of service learning projects. These stakeholders are usually the communities or companies that would benefit directly from service learning projects. Some students encountered problems when they were assigned to the same community or company to carry out their service-learning course requirements every semester.

"Some companies refuse to give their cooperation. We are facing a lack of community cooperation. In addition, arranging a visit to an organization is not an easy task. We have an issue in terms of lack of networking with the Small Medium Enterprises. Moreover, dealing with community leaders also poses a challenge. In certain cases, we have difficulty getting cooperation from the industry and community".

[Student 31]

Moreover, the lecturers also shared similar concerns when trying to establish a cooperative relationship with the community or industry as there were constant contrains to the schedules of both parties involved.

"It is not easy to get collaboration from the targeted community; We (I and the students) have to work smart and hard to get potential communities to participate in our service-learning project. And sometimes, the date execution of the projects cannot be changed due to community constraints. And it clashed with student other academic commitment. The students and I are in dilemma. However, we chose to go on with the project as it is the only date that the community is available."

[Lecturer D] 
The projects that required funding for service learning to be implemented raised further problems in some cases, as can be seen in the viewpoints expressed by the participants:

"It is tough to get sponsor especially when the project involves rural community and the students are racing with time to secure enough fund(ing) to organize the program."

[Student 04]

"It is hard. We have to initiate contact on our own. Moreover, we have to ensure things are smooth running. We did most stuff on our own. I hope the students learned a good lesson from this project. [Lecturer A]

\section{DISCUSSION}

The findings gathered from the analysis of the students' perspective suggested that their lecturers played an integral role in planning and executing service-learning projects. Moreover, it was clear that the lecturers needed to have thorough knowledge on the basic principles of service learning, regardless of whether they were teaching a course that incorporated service learning in theory or in practice. Furthermore, in the attempt to facilitate students' journey from theory to real practice, lecturers themselves are required to understand the philosophy of service learning pedagogy and the importance of scaffolding in experiential learning (Vygotsky, 1987), especially when challenging the students to identify and solve community needs and issues through the service learning approach. Additionally, in order to get students to be more committed and engaged in the service learning project, the lecturers must nurture students' self-confidence when conducting service learning projects. The study conducted by Shephard, Brown and Guiney (2017) highlighted the need to equip the lecturers as course instructors with the right mindset to be fully engaged with the community in any service learning projects.

According to scholars, the success of service learning relies on its careful planning and clear implementation guidelines (Wurdinger \& Allison, 2017; Gerholz, Liszt \& Klingsieck, 2017). Instructors must be ready to provide support to the students when facing any challenges as this is a key factor that ensures success of service learning (Wilson \& Devereux, 2014). The students in the current context are from a teacher-centred education system and collectivist 
social set up, where young individuals have limited opportunities to exercise independent judgment and autonomous functioning (Kaur, et al, 2019). Therefore, to conduct themselves in a novice environment and contribute meaningfully to the context of service learning had posed a serious challenge. Scaffolding was a vital component that would ensure the smooth implementation of service learning projects. Scaffolding can be applied to combine the knowledge and skills between the students and lecturers, or between the students and their peers (Sleeter, Torres \& Laughlin, 2004; Lim et al., 2020). In the study by Sleeter (2004), the facilitators had intentionally scaffolded the students during the process of managing their service learning experiences by providing face to face lectures, developing analytical skills and creating simulations for every activity. Moreover, these facilitators claimed that, through planned scaffolding activities, students were able to achieve the goals of their service learning projects. Due to the uncertainties in the planning and implementation of service learning, scaffolding has shown to be useful but to a certain extent, it needs to be well structured. This is because service learning is closely linked to the course learning outcomes, assessment practises and duration of the service. Therefore, it is crucial for lecturers to know the structured scaffolding techniques, especially for advanced and technical related courses such as mathematics (Ivars, Fenandez \& Llinares, 2020) and engineering (Zheng, Wang \& Yin, 2013) as these disciplines require a fundamental understanding of the basic disciplinary concepts before students can pursue their service learning projects.

The challenges from the lecturers' perspectives revealed that they were overwhelmed with the planning and implementation of service learning. This was due to the lack of structural support needed when undertaking a service learning program. Higher education institutions that implement service learning as an approach in teaching and learning must design courses with the specific purpose of incorporating it not only within the delivery process but also ensure that it relates to the community issues, and assess the methods practised by the participants to gauge the impact of service learning.

Furthermore, the lecturers also shared their concerns on the relevance of structural support. The importance of fostering an institutional culture was highlighted to be beneficial for service learning (Shrader et al., 2008). An optimal institutional culture would provide the training and professional development of staff as it is one of the 
core human resource function to build the necessary knowledge, skills and attitude among the course instructors and other support staff (Bender \& Jordaan, 2007). Moreover, a token of appreciation should be presented to those who extended their service learning efforts for the success of the project, whereby all parties involved should be acknowledged and rewarded with some form of incentive (Vogel, Seifer \& Gelmon, 2010). A cooperative workplace culture can create passionate members in the institutions that could inspire them to contribute more in the future. Additionally, the changing environment in the higher education system require upgrades in infrastructure, and the need to ensure availability of funds to support service learning (Bennet et al., 2016). Although most institutions are facing financial constraints, the top management must find alternative means to influence other stakeholders and industrial players to contribute for the success of service learning implementation.

To further extend accessibility and cooperation from the community, the students and lecturers must establish a trusting relationship with the community. Ideally, a university could establish a centre or department that would act as a liaison between the university and the targeted community. Jenkins and Sheehey (2011) suggested that during the planning stage of a service learning project, the students should be able to identify the community needs, analyse the community resources and establish effective communication channels with them. This would enable the students to identify the suitability of the project, and give due consideration for the needs of the community for a specifically designed service learning project.

Kropp, Arrington and Shankar (2015) highlighted that in order to carry out a successful service learning project, students need to develop and plan sustainable projects that would attend to the needs of the community. This would gain commitment from the community to ensure that the project could solve the pressing issues they faced, and is within the capacity of the students and lecturers to achieve its goals. This is imperative to build complete trust with the community.

\section{CONCLUSION AND RECOMMENDATIONS}

The transformation of teaching and learning from traditional methods to more contemporary innovative ones that engage students in experiential learning to prepare them for future careers in the era of 
the Industrial Revolution 4.0 is an exciting challenge for both students and instructors. Service learning is a creative teaching and learning approach that allows students to cooperate with the community and help solve the issues faced by them. Most importantly, the students would gain a better understanding of the various issues faced by the society and learn from this invaluable opportunity in community engagement.

There are certain challenges that have impeded the implementation of service learning. However, several methods were identified to ensure service learning can be conducted successfully when certain factors are properly addressed through informed decision-making, especially before the implementation of service learning projects. The findings in this study have highlighted the specific issues that lecturers and students faced during the implementation of service learning. It is important to consider both lecturers' and students' perspectives in the attempt to understand the ways to conduct successful service learning projects that would allow students to fully reap the benefits from such experiential learning. Participation in service learning can help build leadership skills among students. When conducted correctly, students become more confident and proud of their contributions toward the community that they served (Barnett, Jeandron \& Patton, 2009). However, students must be supported and guided from their early years in the university to prepare them for the challenges they may face during the service learning implementation.

The implementation of service learning requires total commitment and support from the whole institution (Bennet et al., 2016). Researchers and scholars have highlighted the essential requirements for service learning initiatives to be successful in an institution. These include subject and course designs, assessment, and evaluation (Polin \& Keene, 2010), institutional culture (Shrader et al., 2008), staff training and development (Bender \& Jordaan 2007), acknowledgments and incentives (Vogel, Seifer \& Gelmon, 2010), and infrastructure that supports service learning in higher institutions (Bennet et al., 2016). Furthermore, when selecting a course for service learning, it should be offered to the third or fourth year students as they are more matured and are better equipped with the conceptual knowledge on the subject matter. With regards to assessment, lecturers should be provided flexibility in deciding the kind of assessments that are suitable for service learning projects as this would pave opportunities for instructors to explore the various 
plausible methods of assessment. However, for a more structured and standardized reference, it is suggested that the assessment on service learning should be allocated between $30 \%$ to $100 \%$, with a minimum of 20 hours of student participation in each semester (Department of Higher Education Malaysia, 2019).

There are many initiatives on community and industry engagement in HE such as the Public-private Research Network (PPRN), Centre for University- Industry Collaboration (CUIC) and University Community Transformation Centre (UCTC). The initial focus of these collaborations have been on research partnership for innovations, with little emphasise on learning and teaching. Recently, under the former Minister of Education, the Ministry of Education (now known as MoHE) launched Service Learning Malaysia-University for Society (SULAM) and garnered support from industry players, such as Khind's Foundation, to collaborate in solving various community issues. Khind Foundation has continued to support SULAM projects nationwide through its generous funding to undergraduate students, via a competitive grant application. The Ministry of Higher Education (MoHE) has recently released a SULAM Playbook that was prepared by a taskforce at the national level to spearhead the SULAM movement within the country (Department of Higher Education, 2019). However, apart from such centralized MOHE efforts, each higher education institution should have a clear framework that will help drive effective initiatives to support service learning implementation in its campuses. Nevertheless, this study does present some limitations. For example, the perspectives of university administrators should also be taken into consideration as they will be able to provide important insights that could help improve the understanding of service learning implementation and identify other challenges that may arise from the association between the university and community projects.

\section{ACKNOWLEDGEMENT}

The authors wish to thank the University Teaching and Learning Centre (UTLC), Universiti Utara Malaysia (UUM) for funding this study under the Scholarship of Teaching and Learning Grant Scheme (SoTL), S/O code 14303, and the Research and Innovation Management Centre (RIMC), UUM, Kedah for facilitating this study. 


\section{REFERENCES}

Ahmad, I., Said, H., \& Mohamad Nor, F. (2019). Exploring outcomes of service-learning participation: Evidence from Pakistan. Malaysian Journal of Learning and Instruction, 16(2), 125-154.

Awang-Hashim, R., Kaur, A., \& Valdez, N. P. (2019). Strategizing inclusivity in teaching diverse learners in higher education. Malaysian Journal of Learning and Instruction, 16(1), 105128.

Barnett, L., Jeandron, C., \& Patton, M. (2009). Enriched and inspired: Service pathways tocollege success. Washington. DC: American Association of Community Colleges.

Bender, G., \& Jordaan, R. (2007). Student perceptions and attitudes about community service-learning in the teacher training curriculum. South African Journal of Education, 27(4), 631654.

Bennett, D., Sunderland, N., Bartleet, B., \& Power, A. (2016). Implementing and sustaining higher education servicelearning initiatives. Journal of Experiential Education, 39(2), 145-163.

Borgerding, L. A., \& Caniglia, J. (2017). Service learning within a secondary math and science teacher education program: Preservice mat teachers' perspectives. School Science and Mathematics, 117(1-2), 63-75. https://doi:10.1111/ ssm. 12210

Braun, V., \& Clarke, V. (2006). Using thematic analysis in psychology. Qualitative Research inPsychology, 3(2). Retrieved from http://eprint.uwe.ac.uk/11735

Bringle, R. G., \& Hatcher, J. A. (2000). Institutionalization of service learning in higher education. The Journal of Higher Education, 71, 273-290

Bringle, R. G., \& J. A. Hatcher. (1996). Implementing service learning in higher education Journal of Higher Education, 67, 221-39.

Bringle, R. G., Ruiz, A. I., Brown, M. A., \& Reeb, R. N. (2016). Enhancing the psychology curriculum through service learning. Psychology Learning \& Teaching, 15(3), 294-309. https://doi.org/10.1177/1475725716659966

Bringle, R. G., \& Clayton, P. H. (2020). Integrating service learning and digital technologies: Examining the challenge and 
the promise. RIED. Revista Iberoamericana deEducación a Distancia, 23(1), pp. 43-65. https://doi: http://dx.doi. org/10.5944/ried.23.1.25386

Butin, D. W. (2003). Of what use is it? Multiple conceptualizations of service-learning in education. Teachers College Record, 105(9), 1674-1692.

Butin, D.(2006). The limit of service-learning in higher education. Review of Higher Education, 29(4), 473-498.

Celio, C. I., Durlak, J., \& Dymnicki, A. (2011). A meta-analysis of the impact of service-learning on students. Journal of Experiential Education, 34(2), 164-181.

Chng, H. H., Leibowitz, B., \& Mårtensson, K. (2020). Leading change from different shores: The challenges of contextualizing the scholarship of teaching and learning. Teaching \& Learning Inquiry, 8(1). http://dx.doi.org/10.20343/teachlearninqu.8.1.3

Conway, J. M., Amel, E. L., \& Gerwien, D. P. (2009). Teaching and learning in the social context: A meta-analysis of service learning's effects on academic, personal, social, and citizenship outcomes. Teaching of Psychology, 36, 233-245.

Department of Higher Education Malaysia. (2019) Service learning Malaysia: University for society. Putrajaya: Ministry of Education Malaysia.

Felten, P. (2013). Principles of Good Practice in SoTL. Teaching \& Learning Inquiry: The ISSOTL Journal, 1(1), 121-125. Retrieved from: https://www.jstor.org/stable/10.2979/teachle arninqu.1.1.121?seq=1\#metadata_info_tab_contents

Felten, P., Gardner, J. N., Schroeder, C. C., Lambert, L. M., \& Barefoot, B. O. (2016). The undergraduate experience: Focusing institutions on what matters most. San Francisco: Jossey- Bass, Wiley.

Furco, A. (1996). Service-learning: A balanced approach to experiential education. Washington DC: Corporation for National Service.

Furco, A. (2001). Advancing service-learning at research universities. In M. Carada \& B. W.Speck (Eds.), Developing and implementing service-learning programs. New Directions for Higher Education (No. 114, pp. 67-68). San Francisco: Jossey-Bass.

Gerholz, K-H., Liszt, V., \& Klingsieck, K. B. (2017). Effects of learning design patterns in service learning courses. Active Learning in Higher Education, http://doi/ abs/10.1177/1469787417721420. 
Gibbs, G. (1988). Learning by doing: A guide to teaching and learning methods. Oxford: Further Education Unit.

Gibbs, G. (1994). Teacher efficacy, orientations toward children, and self-esteem: Effects of student teaching (Unpublished doctoral dissertation). Massey University, New Zealand.

Hamilton, D. (2019). Facilitating engagement among academic and community partners: The Monteverde institute's view from the middle. MDPI Social Sciences, 8(121). https:// doi:10.3390/socsci8040121. Retrieved from: https://www. mdpi.com/2076-0760/8/4/121

Hoxmeier, J., \& Lenk, Margarita M. (2020) Service-learning in information systems courses: Community projects that make a difference. Journal of Information Systems Education. 14(1). Retrieved from: https://aisel.aisnet.org/jise/vol14/iss1/10

Hubball, H., \& Clarke, A. (2010). Diverse methodological approaches and considerations for SoTL in higher education. The Canadian Journal for the Scholarship of Teaching and Learning, 1(1). Retrieved from http://ir.lib.uwo.ca/cjsotl_ rcacea/vol1/iss $1 / 2$

Huda, M., Teh, K. S. M., Nor, N. H. M., \& Nor, M. B. M. (2018). Transmitting leadership based civic responsibility: Insights from service learning. International Journal of Ethics and Systems, 34(1), 20-31.https://doi.org/10.1108/IJOES-052017-0079

Hutchings, P., \& Shulman, L. S. (1999). The scholarship of teaching: New elaborations, new developments". Change, 31 (5), 10-15. Retrieved from http://www.carnegiefoundation.org/elibrary/ scholarship-teaching-new-elaborations-newdevelopments

Ivars, P., Fernández, C., \& Llinares, S. A. (2020). Learning trajectory as a scaffold for pre-service teachers' noticing of students' Mathematical understanding. Int $J$ of Sci and Math Educ, 18(1), 529-548. Retrived from: https://doi.org/10.1007/ s10763-019-09973-4

Jacob, S. A., Palanisamy, U. D., \& Chung, C. M. C. (2017). Perception of a privilege walk activity and its impact on pharmacy students' views on social justice in a service learning elective: A pilot study. Journal of Pharmacy Practice and Research, 47(1), 449-456.

Jelinek, K. (2016). Wax on, wax off: Transfer of learning through an experiential learning project. The Accounting Educators' Journal, XXVI, 35-59. 
Jenkins, A., \& Sheehey, P. (2011). A checklist for implementing service-learning in Higher Education. Journal of Community Engagement and Scholarship, 4(2). Retrieved from https:// digitalcommons.northgeorgia.edu/jces/vol4/iss $2 / 6$

Kagan C., \& Diamond J. (2019) Foundations of universitycommunity engagement. In: University-community relations in the UK. Rethinking university-community policy connections. Cham: Palgrave Macmillan.

Karasik, R. (2004). Whispers and sighs: The unwritten challenges of service learning. In S. C. Blossey \& D. Robertson (Eds.), To improve the academy: Resources for faculty, instructional, and organizational development, (pp. 236-253). Bolton, MA: Anker.

Kaur, A, Yusof, N., Awang-Hashim, R., Ramli, R., Dalib, S. Sani, M. A. M. \& Isa, N. M. (2019). The role of developmental assets for prosocial behaviours among adolescents in Malaysia.

Children and Youth Services. 107. https://doi.org/10.1016/j. childyouth.2019.104489

Kelly, B., Margolis, M., McCormack, L., LeBaron, P. A., \& Chowdhury, D. (2017). What affects people's willingness to participate in qualitative research? An experimental comparison of five incentives. Field Methods, 29(4), 333350 .

Khan, T. M., \& Jacob, S. A. (2015) Service learning for pharmacy students: Experience of a home-grown community engagement elective unit. Journal of Pharmacy Practice and Research, 45(3), 314-7.

Kilgo, C. A., Ezell Sheets, J. K., \& Pascarella, E. T. (2015). The link between high-impact practices and student learning: Some longitudinal evidence. High Education, 69, 509-525. https:// doi/10.1007/s10734-014-9788-z

Kropp, J., Arrington, N. M., \& Shankar, V. (2015) Developing a service-learning student facilitator program: Lessons learned. Journal of Community Engagement and Scholarship, 8(1).

Retrievedfrom:https://digitalcommons.northgeorgia.edu/jces/ vol $8 /$ iss $1 / 6$

Krueger, R. A., \& Casey, M. A. (2015). Focus group: A practical guide for applied research. (5th ed). California: Sage.

Lee, W. K., Harris, C., Mortensen, K. A., Long, L. M., \& SugimotoMatsuda, J. (2016). Enhancing student perspectives of humanism in medicine: Reflections from the Kalaupapa service learning project. BMC medical education, 16,137. https://doi:10.1186/s12909-016-0664-7 
Lim, C. L., Ab Jalil, H., Maa'rof, A. M., \& Saad, W. Z. (2020). Selfregulated learning as a mediator in the relationship between peer learning and online learning satisfaction: A study of a private university in Malaysia. Malaysian Journal of Learning \& Instruction, 17(1), 51-75.

Lindlof, T. R., \& Taylor, B. C. (2002). Qualitative communication research methods (2nd ed.). Thousand Oaks, CA: Sage.

Mackenzie, S. L. C., Hinchey, D. M., \& Cornforth, K. P. (2019). A public health service-learning capstone: Ideal for students, academia and community. Front. Public Health, 7(10). https:// doi/10.3389/fpubh.2019.00010. Retrieved from: http s :// www.frontiersin.org/articles/10.3389/fpubh.2019.00010/full

Ministry of Education Malaysia. (2015). Malaysian Education Blueprint 2015-2025 (Higher Education). Retrieved from http://hes.moe.gov.my.

Morin, E. L. (2009). Service learning pitfalls: Problems you didn't see coming. College Teaching Methods \& Styles Journal, 5(1), 43-52.

Musa, N., Abang Ibrahim, D. H., Abdullah, J., Saee, S., Ramli, F., Mat, A. R., \& Ahmad Khiri, M. J. (2017). A methodology for implementation of service learning in higher education institution: A case study from faculty of computer science and information technology, UNIMAS. Journal of Telecommunication, Electronic and Computer Engineering, 9(2), $101-109$.

Nishimura M., \& Yokote H. (2020) Service-learning as a means to understand socio-economic privilege, inequality, and social mobility. In Sanger C., Gleason N. (eds). Diversity and inclusion in global higher education. Palgrave Macmillan, Singapore.

Organization for Economic Co-operation and Development (1996). Transition to learning economies and societies. OECD: Paris, France.

Parker, E. A., Myers, N., Higgins, H. C., Oddsson, T., Price, M., \& Gould, T. (2009). More than experiential learning or volunteering: A case study of community service 1 e a r $n$ i n within the Australian context. Higher Education Research \& Development, 28(6), 585-596.

Pike, G. R., Kuh, G. D., \& McCormick, A. C. (2010). An investigation of the contingent relationships between learning community participation and student engagement. Research in Higher Education, 52(3), 300-322. 
Polin, D. K., \& Keene, A. S. (2010). Bringing an ethnographic sensibility to service-learning assessment. Michigan Journal of Community Service Learning, 16(2), 22-37.

Richard, D., Keen, C., Hatcher, J. A., \& Pease, H. A. (2017). Pathways to adult civic engagement: Benefits of reflection and dialogue across difference in higher education s ervicelearning programs. Michigan Journal of Community Service Learning, 23(1), 60-74.

Salam, M., Iskandar, D. N. F. A., \& Ibrahim, D. H. A. (2017). Service learning support for academic learning and skills development. Journal of Telecommunication, Electronic and Computer Engineering (JTEC), 9(2-10), 111-117.

Salam, M., Awang Iskandar, D. N., Ibrahim, D. H. A., \& Farooq, M. S. (2019a). Technology integration in service-learning pedagogy: A holistic framework. Telematics and Informatics, 38(1), 257-273.

Salam, M., Awang Iskandar, D. N., Abang Ibrahim, D. H., \& Farooq, M. S. (2019b). Service learning in higher education: A systematic literature review. Asia Pacific Education Review, 20(1), 573-593. https://doi.org/10.1007/s12564-019-09580-6

Sax, L., \& Astin, A. (1997). The benefits of service: Evidence from undergraduates. Educational Record, 78, 25-32.

Shephard, K., Brown, K., \& Guiney, T. (2017). Researching the professional-development needs of community-engaged scholars in a New Zealand University. Sustainability, 9(7), 1249. https://doi.org/10.3390/su9071249

Shrader, E., Saunders, M. A., Marullo, S., Benatti, S., \& Weigert, K. M. (2008). Institutionalizing community-based learning and research: The case for external networks. Michigan Journal of Community Service Learning, 14(2), 27-40.

Shulman, L. S. (2001). Remarks at the teaching symposium for the cross endowed chair for the scholarship of teaching and learning. Normal, IL: Illinois State University.

Sleeter, C., Torres, M., \& Laughlin, P. (2004). Scaffolding conscientization through inquiry in teacher education. Teacher Education Quarterly, 31(1), 81-96.

Taylor, A. (2017). Service-learning programs and the knowledge economy: Exploring the tensions. Vocations and Learning, 10(1), 253-273.

Tryon, E., Stoecker, R., Martin, A., Seblonka, K., Hilgendorf, A., \& Nellis, M. (2008). The challenge of short-term service- 
learning. Michigan Journal of Community Service Learning, 14(2), 16-26.

Vogel, A. L., Seifer, S. D., \& Gelmon, S. B. (2010). What influences the long-term sustainability of service-learning? Lessons from early adopters. Michigan Journal of Community Service Learning, 17(1), 59-74.

Vygotsky, L. S. (1987). Thinking and speech. In L. S. Vygotsky, R. W. Rieber (Series Eds.), \& A. S. Carton (Vol. Ed.), The collected works of L. S. Vygotsky. Vol. 1: Problems in general psychology (N. Minick, Trans.). New York: Plenum.

Wang, J., Patten, E., Shelby, R., Ansari, F., \& Pruitt, L. (2012) Leadership and service learning improves confidence of engineering skills in women. Proceedings from the $119^{\text {th }}$ ASEE Annual Conference \& Exposition, San Antonio, TX.

Wilson, K., \& Devereux, L. (2014). Scaffolding theory: High challenge, high support in Academic Language and Learning (ALL) contexts. Journal of Academic Language and Learning, 8(3), A91-100.

Wurdinger, S., \& Allison, P. (2017). Faculty perceptions and use of experiential learning in higher education. Journal of E-Learning and Knowledge Society, 13(1), 15-26.

Xu, C., Li, H., \& McDougle, L. M. (2018). Experiential philanthropy. In GlobalEncyclopedia of Public Administration, Public Policy, and Governance (pp. 1-7). Ch a m, S w i t z e r 1 and: Springer International Publishing. https://doi: 10.1007/978-3319-31816-5_3048-1

Yusop, F. D., \& Correia, A. P. (2013). The benefits and challenges of implementing service-learning in an advanced instructional design and technology curricula: Implications for teaching professional courses. The New Educational Review, 32(2), 220-232.

Zheng, W., Wang, M. L., Yin, J. (2013). Correlation analysis of scaffolding creative problem solving through question prompts with process and outcomes of project-based service learning. In Proceedings of the 120th ASEE annual conference and exposition. American Society for Engineering Education, Atlanta.

Ziegert, A., \& McGoldrick, K. (2008). When service is good for economics: Linking the classroom and community through service learning. International Review of Economics Education, 7(2), 39-56. 